\title{
Silicosis in a Himalayan village population: role of environmental dust
}

\author{
T Norboo, P T Angchuk, M Yahya, S R Kamat, F D Pooley, B Corrin, I H Kerr, \\ N Bruce, K P Ball
}

\begin{abstract}
The Himalayan villages of Chuchot Shamma and Stok were surveyed because silicosis had been suspected from the radiographs of some of the inhabitants. The villages are agricultural, and Chuchot is exposed to frequent dust storms. Chest radiographs of villagers aged $50-62$ were assessed blind by two independent observers using ILO criteria. In Chuchot five of seven men and all of the nine women examined showed varying grades of silicosis, compared with three of 13 men and seven of 11 women in Stok, which lies $\mathbf{3 0 0}$ metres higher and is exposed to fewer dust storms. The difference in prevalence of silicosis between the two villages was significant, as was the differences between men and women. Three patients from the village adjoining Chuchot were later found to have radiological evidence of progressive massive fibrosis. A necropsy on a man in a neighbouring village in the Indus valley showed classical silicosis in a hilar lymph node. Chemical analysis of the inorganic dust in the lung showed that $54 \cdot 4 \%$ was elemental silicone. This was similar to the silicone content of dust samples collected from houses in Chuchot, which included particles of respirable size. $X$ ray microanalysis showed that quartz formed $16-21 \%$ of the inorganic lung dust. This study suggests that silicosis is common among the older inhabitants of these Himalayan villages. The dust exposure is clearly environmental and not industrial. Further studies are needed to define the extent and severity of silicosis in this community and to examine possible preventive measures.
\end{abstract} Hospital, London NW10 7NS

K P Ball

Royal Brompton and National Heart and Lung Hospital, London SW3 6NP

I H Kerr

B Corrin

Royal Free Hospital, London NW3 2QG N Bruce

Reprint requests to

Dr Norboo (India) or Dr Ball (The Studio, Mount Park Road, London W5 2RP)

Accepted 15 February 1991

some years local doctors have been cerned at the frequency of chest disease in some villages of the Indus valley in Ladakh, a high altitude region of the Himalayas in north west India. Some chest radiographs had suggested the presence of silicosis. To investigate the problem further we have tried to determine whether radiological evidence of silicosis is common, and whether environmental dust could be the cause.

\section{Methods}

STUDY VILLAGES AND SUBJECTS

The survey was carried out in two villages situated about $15 \mathrm{~km}$ from Leh, the capital of Ladakh. The first village, Chuchot Shamma, lies in the Indus valley at an altitude of $3200 \mathrm{~m}$ and is subject to frequent dust storms in spring, which can be so dense as to obscure nearby mountains. The second village, Stok, lies $6 \mathrm{~km}$ away and, being $300 \mathrm{~m}$ higher, is less exposed to dust storms. Both villages are mainly farming communities, each with a population of about 1000 . The women are more heavily exposed to dust because they do most of the farming work and they sweep the dusty houses and carry baskets of earth for the traditional toilets. The houses have mud floors and are often smoky owing to the lack of an effective chimney. There is no occupational or other exposure to dust. About $20 \%$ of the men but none of the women smoke cigarettes.

Subjects aged 50-62 were drawn from the electoral list of both villages. From Chuchot Shamma every third man and every second woman and from Stok every second man and woman was selected. Each person was invited to Leh for radiographic chest examination; seven out of 10 men and nine out of 12 women from Chuchot Shamma and all 13 men and 11 women from Stok responded.

\section{INVESTIGATIONS}

Radiographs were read blind and independently by two radiologists (SRK and IHK), who used the shortened ILO classification. ${ }^{1}$

Necropsy material later became available from a Ladakhi resident in a neighbouring village in the Indus valley. He was a musician aged 60 years who had suffered a violent death. Lung tissue and hilar glands were examined pathologically and representative portions digested for dust analysis.

Dust from the upper surfaces of beams in three houses in Chuchot Shamma and the pathological specimens were analysed by means of a transmission electron microscope equipped for $x$ ray diffraction and energy dispersive $x$ ray analysis.

\section{ANALYSIS}

Statistical significance was tested with Fisher's exact test. Two tailed values were obtained by doubling the probability of the observed or more extreme values. 
Figure 1 Chest

radiograph of a Chuchot woman aged 56 with a winter cough and shortness of breath on heavy exercise. There were no abnormal signs when her chest was examined. Her $F E V$, was $1.5 l$ and forced vital capacity $2.4 \mathrm{l}$ with a ratio of $62 \%$. The chest radiograph shows extensive nodular opacities in all zones consistent with simple silicosis, ILO grade 3.

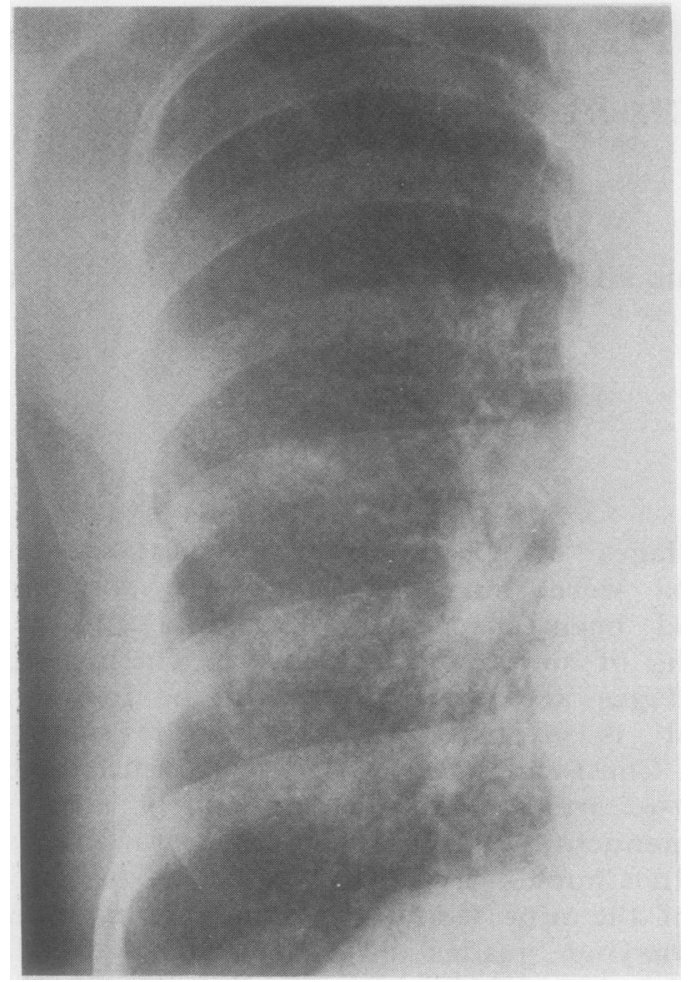

\section{Results}

Radiographic findings

There was good agreement between the two radiologists who interpreted the films, with complete agreement for 23 of the 39 radiographs and disagreement by more than one grade in only one case. On the basis of the interpretation of one radiologist (IHK) nodular opacities consistent with silicosis were found in subjects from both villages (fig 1) but they were more pronounced in Chuchot Shamma than in Stok (14/16 in Chuchot but only 10/24 in Stok: $\mathrm{p}<0.01)$. The opacities were also more frequent in women than in men (16/20 women compared with $8 / 20$ men: $p<0.025$-table). All the women in Chuchot showed nodular opacities and at least two women and one man had egg shell calcification of hilar nodes (fig 2). Large opacities were more frequent in Chuchot Shamma (7/16) than in Stok (1/24) (table) and, although in some of these cases silicosis could not be distinguished with certainty from tuberculosis, most of the opacities were considered to represent silicosis. Shortly after the survey three patients from the village adjoining Chuchot Shamma who were very short of breath were found to have radiological evidence of progressive massive fibrosis (fig 3).

Radiological grades of silicosis in the two villages $\star$

\begin{tabular}{llllll}
\hline & \multicolumn{2}{l}{ Chuchot Shamma } & & \multicolumn{2}{l}{ Stok } \\
\cline { 2 - 3 } \cline { 5 - 6 } $\begin{array}{l}\text { ILO } \\
\text { grade }\end{array}$ & $\begin{array}{l}\text { Men } \\
(n=7)\end{array}$ & $\begin{array}{c}\text { Women } \\
(n=9)\end{array}$ & $\begin{array}{l}\text { Men } \\
(n=13)\end{array}$ & $\begin{array}{l}\text { Women } \\
(n=11)\end{array}$ \\
\hline 0 & $2(0)$ & $0(0)$ & & $10(0)$ & $4(0)$ \\
1 & $3(1)$ & $3(1)$ & & $3(1)$ & $4(0)$ \\
2 & $2(1)$ & $5(4)$ & & $0(0)$ & $3(0)$ \\
3 & $0(0)$ & $1(0)$ & & $0(0)$ & $0(0)$ \\
\hline
\end{tabular}

^Figures in parentheses indicate the presence of larger opacities compatible with either tuberculosis or silicosis but in most cases thought to represent the latter.

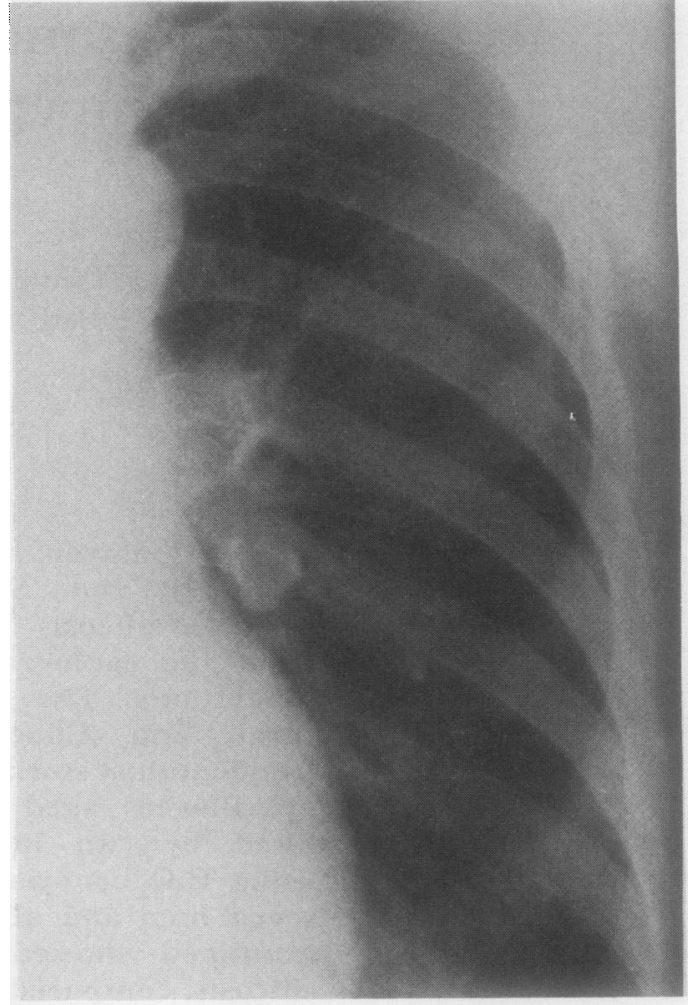

Figure 2 Chest radiograph of a Chuchot man aged 55 with winter cough and sputum. He had previously been treated for pulmonary tuberculosis. His FEV, was $1 \cdot 1 \mathrm{l}$ and forced vital capacity $1.3 \mathrm{l}$ with a ratio of $84 \%$. The chest radiograph shows nodular opacities consistent with silicosis grade 2, with well marked egg shell changes in the left hilar lymph nodes.

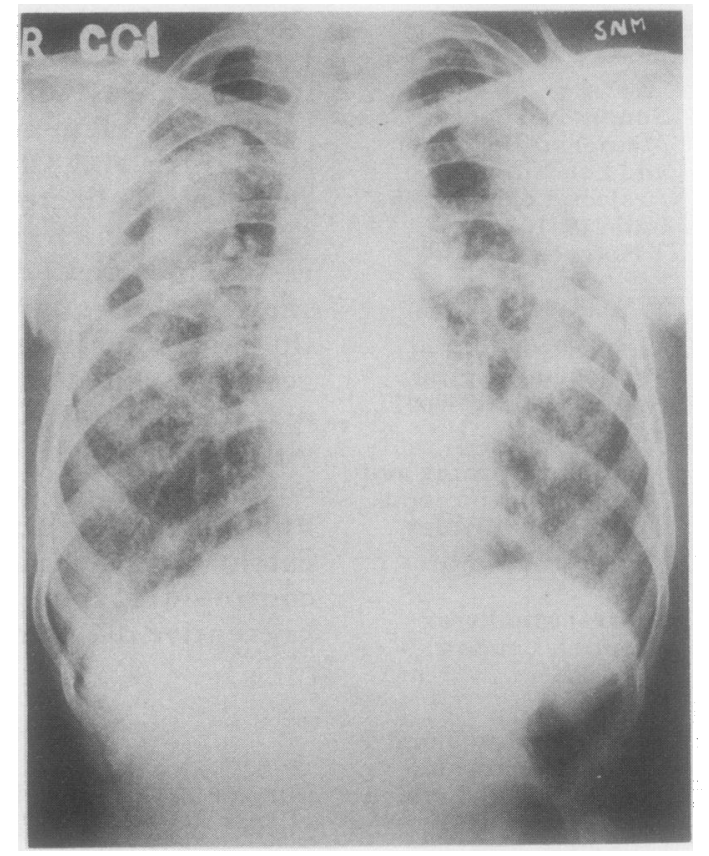

Figure 3 Chest radiograph of a 51 year old woman farmer, who had had chronic cough, sputum, and breathlessness on mild exertion for three years. She could no longer work outside and could only manage milking the no longer work outside and could only manage milking the capacity $1.47 \mathrm{l}$ with a ratio of $94 \%$. Her

electrocardiogram was normal. The chest radiograph shows conglomerate opacities consistent with progressive massive fibrosis. 
PATHOLOGICAL FINDINGS

Two slices of lung were received. The lung parenchyma was studded with numerous black nodules measuring 1-2 $\mathrm{mm}$ across. A hilar lymph node measuring $1.5 \mathrm{~cm}$ across was black and hard. Microscopic examination of the lungs and lymph node showed heavy deposition of black dust, which in the lung was aggregated focally as centriacinar collections. With polarising filters many birefringent particles were evident among the black dust. The hilar lymph node was largely replaced by whorled hyaline collagenous nodules, the classic appearance of silicosis. In the lungs most of the dust deposits were not associated with fibrosis but a few showed a little hyaline collagenous deposition. These nodules were stellate in outline, showing the appearance of early mixed dust pneumoconiosis. Gravimetric analysis of lung tissue and the residue after tissue digestion and ashing showed that inorganic dust accounted for $141.7 \mathrm{mg} / \mathrm{g}$ of dry lung.

\section{DUST ANALYSIS}

$X$ ray diffraction showed that $20.8 \%$ of the inorganic dust extracted from the lungs consisted of quartz. Energy dispersive $x$ ray analysis of the inorganic lung dust showed $61 \cdot 1 \%$ muscovite (a mica), $15 \cdot 7 \%$ quartz, $7 \cdot 4 \%$ feldspar, $5.6 \%$ albite, $2 \cdot 8 \%$ biotite, $1.9 \%$ titanium, and $0.9 \%$ chlorite. Bulk chemical analysis of the lung dust showed that it consisted of $54 \%$ elemental silicone, $19 \cdot 2 \%$ aluminium, and $10.9 \%$ iron, other elements accounting for $14.5 \%$ (each percentage referring to the oxide). These figures are similar to those for the environmental samples.

Dust taken from the living rooms of Chuchot houses included many particles within the range $0.5-5 \mu \mathrm{m}$ diameter. Bulk chemical analysis showed that elemental silicone accounted for about half of each sample (on the basis of the oxides of the elements). The major single particle type in each of the village samples was muscovite (mica), followed by chlorite and quartz, a composition similar to that of the dust recovered from the lung sample.

\section{Discussion}

This study shows that radiological appearances strongly suggesting silicosis are widespread among the older inhabitants of Chuchot Shamma and to a lesser extent Stok. Stok is less exposed to dust storms. As these communities are agricultural the dust exposure cannot be attributed to industrial sources.

Non-industrial deposition of silica in the lungs was first reported by Policard and Collet ${ }^{2}$ in three inhabitants of the Sahara desert, and sand silicosis was subsequently reported from the Libyan desert. ${ }^{3}$ Similar findings have been found elsewhere, ${ }^{4-7}$ including in Egyptian mummies. ${ }^{8}$ Deposition of silica in association with fibrosis has been described in the lungs of
Californian farm workers, zoo animals, and horses; it is suggested that simple silicate pneumoconiosis is common in people living in desert or semi-desert climates. ${ }^{9-11}$

Our findings support the evidence that silicosis may develop when people are exposed to desert dust. Although cough and sputum were found in many of the villagers in this study those with radiological evidence of simple silicosis did not appear to have more symptoms than those without. The finding of three cases of progressive massive fibrosis suggests that silicosis in these communities may cause appreciable morbidity. We have been unable to find any previous reports of nonoccupational progressive massive fibrosis.

This preliminary report suggests that silicosis is widespread among older people exposed to environmental dust and that it may result in advanced fibrotic lung disease associated with disability. Women, who are more heavily exposed to dust in the course of their work, appear to be more commonly affected than men.

Reduction of dust exposure in this community would be difficult to achieve. This emphasises the need to prevent respiratory disease caused by other factors, such as cigarette smoking and smoke pollution from fires in the home. A larger study covering a wider range of communities and including assessment of symptoms, sputum examination, and lung function tests, is required to determine the public health importance of silicosis in Ladakh.

We are grateful to Dr A Staton-Bevan for ascertaining that the environmental dust was of respirable size; to Dr J A Heady for statistical advice; to Dr Stanzin Tundup, medical superintendent of the Sonam Norboo Memorial Hospital; to Nazir Ahmed, Haji Ghulam Abbas, and Annupam Saraf for radiography carried out under difficult conditions; and to the cardiothoracic research fund, Central Middlesex Hospital.

1 International Labour Office. International classification of radiographs of pneumoconiosis. Geneva: ILO, 1980.

2 Policard A, Collet A. Deposition of silicosis dust in the lungs of the inhabitants of the Sahara regions. Arch Ind Hyg Occup Med 1952; 5:527-34.

3 Fossati C. Sulla possibilità e sulla frequenza della silicosi pulmonare tra gli abitanti del deserto libico. Med Lav 1969;60:144-9.

4 Hirsch M, Bar-Ziv J, Lehmann E, Goldberg GM. Simple siliceous pneumoconiosis of Bedouin females in the Negev desert. Clin Radiol 1974;25:507-10.

5 Bar-Ziv J, Goldberg G. Simple siliceous pneumoconiosis in Negev Bedouins. Arch Environ Health 1974;29:121-6.

6 Fennerty A, Hunter AM, Smith AP, Pooley FD. Silicosis in a Pakistani farmer. BMJ 1983;ii:648.

7 Hawass ND. Non-occupational pneumoconiosis (desert lung). In: Capesius P, ed. Proceedings of XVth International Congress of Radiology. Chest and Breast. Luxembourg: Interimages, 1983:280-5.

8 Tapp E, Curry A, Anfield C. Sand pneumoconiosis in an Egyptian mummy. BMJ 1975;ii:276.

9 Sherwin RP, Barman ML, Abraham JL. Silicate pneumoconiosis of farm workers. Lab Invest 1979;40: 576-82.

10 Brambilla C, Abraham J, Brambilla E, Benirschke K, Bloor C. Comparative pathology of silicate pneumoconiosis. Am $J$ Pathol 1979;96:149-70.

11 Schwartz LW, Knight HD, Whittig LD, Malloy RL, Abraham JL, Tyler NK. Silicate pneumoconiosis and pulmonary fibrosis in horses from the Monterey-Carmel peninsula. Chest 1981;80:82-5S. 


\section{LETTERS TO THE EDITOR}

Risk of tuberculosis in immigrant Asians: culturally acquired immunodeficiency

I was interested to see that in the paper by $\mathrm{Dr}$ PJ Finch and colleagues (January 1991;46:15) the theory that vitamin $D$ deficiency causes immunosuppression and increased host susceptibility to tuberculosis was put forward as a possible cause of the increased incidence of tuberculosis, particularly glandular tuberculosis, in Hindu immigrants. ${ }^{\text {Perhaps }}$ because of the authors' gastroenterological interests they see dietary factors as a major cause of vitamin deficiency and therefore susceptibility to disease. Dietary patterns, however, probably do not differ greatly between Britain and their country of origin, and are therefore unlikely to make much contribution to the cause of this apparent "acquired immunodeficiency of immigration." A Hindu Vegan in Wandsworth was probably a Hindu Vegan in India. Vitamin D reduction due to decreased exposure to sunlight on immigration to Britain, however, may well be a major factor. Mean serum vitamin $\mathrm{D}$ concentrations $\left(25(\mathrm{OH}) \mathrm{D}_{3}\right)$ have been shown to drop four-fold, or more, on emigration from Asia to Britain.'

Asian individuals with tuberculous infection who are able to contain the infection because of satisfactory host immunity while in their sunny country of origin suffer a dramatic fall in the storage form of vitamin $\mathrm{D}$ $25(\mathrm{OH}) \mathrm{D}_{3}$ on emigrating to the United Kingdom. In some individuals this may affect local production of the active hormone $1,25(\mathrm{OH})_{2} \mathrm{D}_{3}$, resulting in a relative decline of lymphocyte and macrophage activation. ${ }^{2}$ The previously contained infection then causes overt disease. This would explain why most individuals present within a relatively short time (five years) of arrival in Britain.

The fact that the pattern of tuberculosis in HIV positive patients seems to resemble the pattern of disease in Asian individuals in Britain has been pointed out before." The sequence of events is probably similar in these patients. An individual with tuberculosis infection becomes immunocompromised (either from HIV infection or from vitamin D reduction) and the extrapulmonary and glandular pattern of disease emerges.

Much more detailed work on the immunology of both tuberculosis and HIV infection is needed; it may even be that vitamin $D$ has a role in the treatment of AIDS.

PDO DAVIES South Liverpool Chest Clinic, Sefton General Hospital, Liverpool L15 $2 \mathrm{HE}$

1 Rashid A, Mohammed T, Stephens WP, Warrington S, Berry JL, Mauren EB. Vitamin $\mathrm{D}$ state of Asians living in Pakistan. BMJ 1983;286:182-4.

2 Rook GAW. The role of vitamin D in tuberculosis. Am Rev Respir Dis 1988;138:768-70.

3 Davies PDO. Vitamin D and tuberculosis. $\mathrm{Am}$ Rev Respir Dis 1989;139:1571.
AUTHORS' REPLY We are grateful to $\mathrm{Dr}$ Davies for his letter and support for our suggestion that vitamin D lack and resultant decline in monocyte activation may be important in explaining the pronounced differences in risk of tuberculosis among Asian immigrants in the United Kingdom. We accept that Asian dietary practices are unlikely to change with emigration, but it has been shown that where exposure to the sun is limited the risk of metabolic bone disease is determined by dietary factors. 'In a prospective study of Asians presenting to a general medical outpatient clinic in Wandsworth we have found that osteomalacia is almost exclusively a disease of vegetarian Hindu Asians, and we believe that this may help to explain why it is the Hindus who are at particular risk of developing tuberculosis rather than the Muslims, who have very similar exposure to the sun.

The mechanism by which vegetarianism may produce vitamin $\mathrm{D}$ deficiency is not clear as the contribution of ingested ergocalciferol to the physiological economy of vitamin $\mathrm{D}$ is thought to be negligible. It has been suggested that calcium depletion caused by binding to fibre and phytate may lead to secondary hyperparathyroidism and accelerated catabolism of 25-hydroxy vitamin D. ${ }^{2}$ Another possibility is that the absence of the normal dietary inducers of hepatic mixed function oxidases found in meat, eggs, and cheese may constrain the hydroxylation of cholecalciferol.

$$
\begin{array}{r}
\text { PJ FINCH } \\
\text { FJC MILLARD } \\
\text { JD MAXWELL } \\
\text { Department of Biochemical Medicine, } \\
\text { St George's Hospital Medical School, } \\
\text { London SW17 ORE }
\end{array}
$$

1 Henderson JB, Dunnigan MG, McIntosh WB, Abdul-Motaal AA, Hole D. Asian osteomalacia is determined by dietary factors when exposure to ultra-violet radiation is restricted-a risk factor model. $Q J \mathrm{Med}$ 1990;281:923-33.

2 Clements MR, Johnson L, Fraser DR. A new mechanism for induced vitamin $\mathrm{D}$ deficiency in calcium deprivation. Nature 1987;325: $62-5$.

3 Dollery CT, Fraser HS, Davies D, Macintyre I. Vitamin D status in different subgroups of British Asians. Br Med J 1977;i:104.

Measures of reversibility in response to bronchodilators in chronic airflow obstruction

Drs DC Weir and PS Burge (January 1991; 46:43-5) have looked at various indices of reversibility in response to bronchodilators in chronic airflow obstruction and correlated these indices with the prebronchodilator forced expiratory volume in one second $\left(F_{E V}\right)$. They showed that two out of the four indices of reversibility they used correlated with prebronchodilator $\mathrm{FEV}_{1}$. It is, however, doubtful whether their analysis and conclusions are valid.

The difficulty in interpreting this type of data is that the indices of reversibility all include prebronchodilator $\mathrm{FEV}_{1}$. This value therefore influences both of the variables being correlated. A significant association is thus likely to arise because of this mathematical association alone. This is not to deny that there may be a true biological association between prebronchodilator $\mathrm{FEV}_{1}$ and one or more of the indices of reversibility, but it is likely to be masked by the mathematical association.
The vexed subject of examining the relation between a measurement and its change after a therapeutic intervention is one that regularly surfaces. ${ }^{12}$

\section{GE PACKE Chest Clinic City Hospital Aberdeen $A B 98 A L$}

1 Oldham PD. A note on the analysis of repeated measurements of the same subject. J Chronic Dis 1963;15:969-77.

2 Gill JS, Zezulka AV, Beevers DG, Davies P. Relation between initial blood pressure and it fall with treatment. Lancet $1985 ; \mathrm{i}: 567-9$.

AUTHOR'S REPLY I thank Dr Packe for raising this point, but believe that our conclusions are still valid. The inclusion of prebronchodilator $\mathrm{FEV}_{\text {, }}$ in each index may well cause a correlation to be present because of mathematical rather than biological association. Hence it is difficult to know if the statistically significant correlations seen between prebronchodilator FEV, and reversibility, expressed as a percentage of the initial $\mathrm{FEV}_{1}$ or as a percentage of the "possible" reversibility, reflect true biological association. But as reversibility expressed as the absolute change in FEV, and reversibility as a percentage of the individual's predicted FEV, show no significant correlation it would appear preferable to use either of these indices if a measure independent of $F E V_{1}$ is needed.

DAVID C WEIR Department of Respiratory Medicine, East Birmingham Hospital, Birmingham B9 5ST

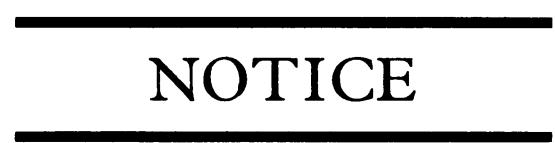

\section{Thoracic surgery review course}

The second biennial thoracic surgery review course will be held in Birmingham on 12 and 13 October 1991. Details and application forms may be obtained from Universal Conference Consultants, 145-14T Alcester Road, Birmingham B13 8JP (021 442 4307).

\section{CORRECTION}

Hut lung: a domestically acquired pneumoconiosis of mixed aetiology

Silicosis in a Himalayan village population: role of environmental dust

We regret that "silicon" is misspelt as "silicone" in these two papers-in the first paper, by Drs JP Grobbelaar and ED Bateman (May 1991;46:334-40), on page 339, column 1, line 5; and in the second paper, by Dr T Norboo and others (May 1991;46: $341-3$ ), on page 341 , lines 28 and 29 of the abstract, and on page 343, lines 9 and 17 of "Results." 